\title{
DECISION MODEL FOR SELECTION OF MODERNIZATION MEASURES: PUBLIC BUILDING CASE
}

\author{
Romas RASIULIS ${ }^{\mathrm{a}}$, Leonas USTINOVICHIUS ${ }^{\mathrm{b}}$, Tatjana VILUTIENE ${ }^{\mathrm{a}}$, Vladimir POPOV ${ }^{\mathrm{a}}$ \\ ${ }^{a}$ Vilnius Gediminas Technical University, Sauletekio al. 11, LT-10223 Vilnius, Lithuania \\ ${ }^{b}$ Bialystok University of Technology, ul. Wiejska 45a, 15-351 Bialystok, Poland
}

Received 17 Jul 2015; accepted 02 Nov 2015

\begin{abstract}
The aim of our study is to present the decision model for selection of optimal combinations of modernization measures. The presented algorithm of decision synthesis method comprises method for integrated significance determination of efficiency indicators and multiple criteria decision methods. The paper also presents the case study illustrating the application of proposed model. As the alternative modernization measures can generate many alternative combinations the decision tree model was proposed as an efficient tool facilitating the analysis of big data and included in algorithm. Three multiple criteria decision support methods based on quantitative measurements included in algorithm used to increase the reliability of the decision. The proposed algorithm is very suitable for evaluation of modernization decisions of the building and enables decision-maker to select the best performing alternative in terms of energy consumption, cost of instalment and other relevant criteria.
\end{abstract}

Keywords: modernization, passive building constructions, decision synthesis method, SyMAD-3, TOPSIS, SAW, COPRAS.

\section{Introduction}

The recast of Directive 2010/31/EU on the Energy Performance of Buildings (EPBD 2010) introduces a European-wide definition of "nearly zero energy buildings" and indicates that the new buildings will have to be nearly zero energy buildings by 31 st December 2020 with public buildings having to fulfil this standard two years earlier. Nearly zero energy buildings are now defined in the EPBD as constructions that have "a very high energy performance". Directive encourages architects and planners to consider properly the optimal combination of improvements in energy efficiency and search for more sustainable solutions. The vision of sustainable building was discussed in the last decade (Gimenez et al. 2012; Wang, Adeli 2014; Žèkas et al. 2014; Kang 2015; Medineckiene et al. 2015 and others) pointing that a successful creation of sustainable infrastructure systems and environmentally conscious designs requires a holistic, integrated, and multidisciplinary approach.

The buildings sector is the largest energy-consuming sector, accounting for over one-third of final energy consumption globally and an equally important source of $\mathrm{CO}_{2}$ (carbon dioxide) emissions (IEA 2013). Trends of energy use in buildings are directly related to the renovation of energy supply infrastructure, new construction, refurbishment of old buildings, maintenance and replacement of heating, ventilation and cooling equipment. Yet, by far most energy is consumed not for construction but during the use the buildings. Currently, space heating and cooling together with water heating are estimated to account for nearly $60 \%$ of global energy consumption in buildings. They therefore represent the largest opportunity to reduce buildings energy consumption and reduce $\mathrm{CO}_{2}$ emissions.

Poor thermal performance of building envelope during use has also influence on high-energy consumption for heating and high heating expenditures. The building envelope determines the amount of energy needed to heat and cool a building, and hence needs to be optimised to keep heating and cooling loads to a minimum. International Energy Agency (IEA 2013) estimated that a highperformance building envelope in a cold climate requires just $20 \%$ to $30 \%$ of the energy required to heat the current average building. More than $40 \%$ of the savings expected in heating and cooling energy demand under a low-carbon scenario can be directly attributable to improvements in the building envelope.

Recent studies (Mahdavi, Tahmasebi 2015; Martinaitis et al. 2015) revealed that occupants' behaviour significantly affects building energy consumption and have

Corresponding author: Tatjana Vilutiene

E-mail: tatjana.vilutiene@vgtu.lt 
also be taken into account in predicting energy consumption of buildings even on design stage. Many studies reported that the assurance of comfortable indoor conditions is the main goal of the building modernization (Dzeng et al. 2015; Aja et al. 2015; Friege, Chappin 2014; Mjoernell et al. 2014). The indoor climate has become a big concern due to more indoor time spending (Wang et al. 2011). The thermal comfort parameters of the majority of old construction buildings do not meet the requirements of hygiene norms, and that is the one of the reasons why buildings need to be modernized. It is known that small temperature fluctuations cause the movement of air and very large temperature difference causes cold symptoms. It is necessary to avoid the peaks of temperature for the microclimate to be more comfortable. The ventilation is necessary in order to eliminate unpleasant odours and to reduce the accumulated moisture. The indoor humidity is also important, because if it exceeds $70 \%$ and if less than $40 \%$ the conditions are considered as negative. The installation of the additional thermal insulation allows saving energy for heating. Significant decrease in energy consumption could be achieved if the building before refurbishment was not insulated (Ham, Golparvar-Fard 2015; Kim et al. 2009; Lombera, Rojo 2010; Wong, Fan 2012).

Although scientific community recently discusses the concept of ecological modernization (Bayulken, Huisingh 2015) the developing countries with emerging economies are forced to short-sighted urban development models due to significant economic pressures. As a rule, the income of residents living in old apartment buildings is almost equal to the expenses for heating, and in some cases, the amount paid for heating exceeds the rent. Then the state is obliged to cover the heating costs of socially supported residents with low-income level. In such situation the governments more likely to ignore ecological implications and inclined to give importance to the energy, social and economic aspects of modernization (Stankevičius et al. 2014). Therefore, the studies focusing on economic aspects of modernization are still relevant. Bearing in mind the financial constraints Bucoń and Sobotka (2015) developed a decision-making model for choosing the repair solutions for the most costeffective scope supporting the decision-maker in multiple criteria building appraisal and the choice of the optimal repair solution. Taking into account the aforementioned regional specifics, the authors raised the aim to find the most suitable decision model to evaluate the modernization alternatives in term of energy conservation and economic aspects. The paper presents the decision model for selection of alternative combinations of modernization measures and case study illustrating the application of proposed model.

\section{The decision model}

Decision-making based on the analysis of a number of problems or their synthesis often requires the integration of several problems into a coherent whole (Šarka et al. 2008). The concept of synthesis in decision-making was used in number of researches (Srdjevic, B., Srdjevic, Z. 2013; Simanaviciene et al. 2012; Simanaviciene, Ustinovichius 2012 and others). Decision-making by using the methods of synthesis requires step-by-step selection of the most effective option from a generated set of alternatives. The decision model used for selection of alternative combinations of modernization measures in this study presented in Figure 1.

First, building and energy experts perform the building audits and collect the data on existent condition of building. Collected building data stored in database together with data on available construction materials, tech-

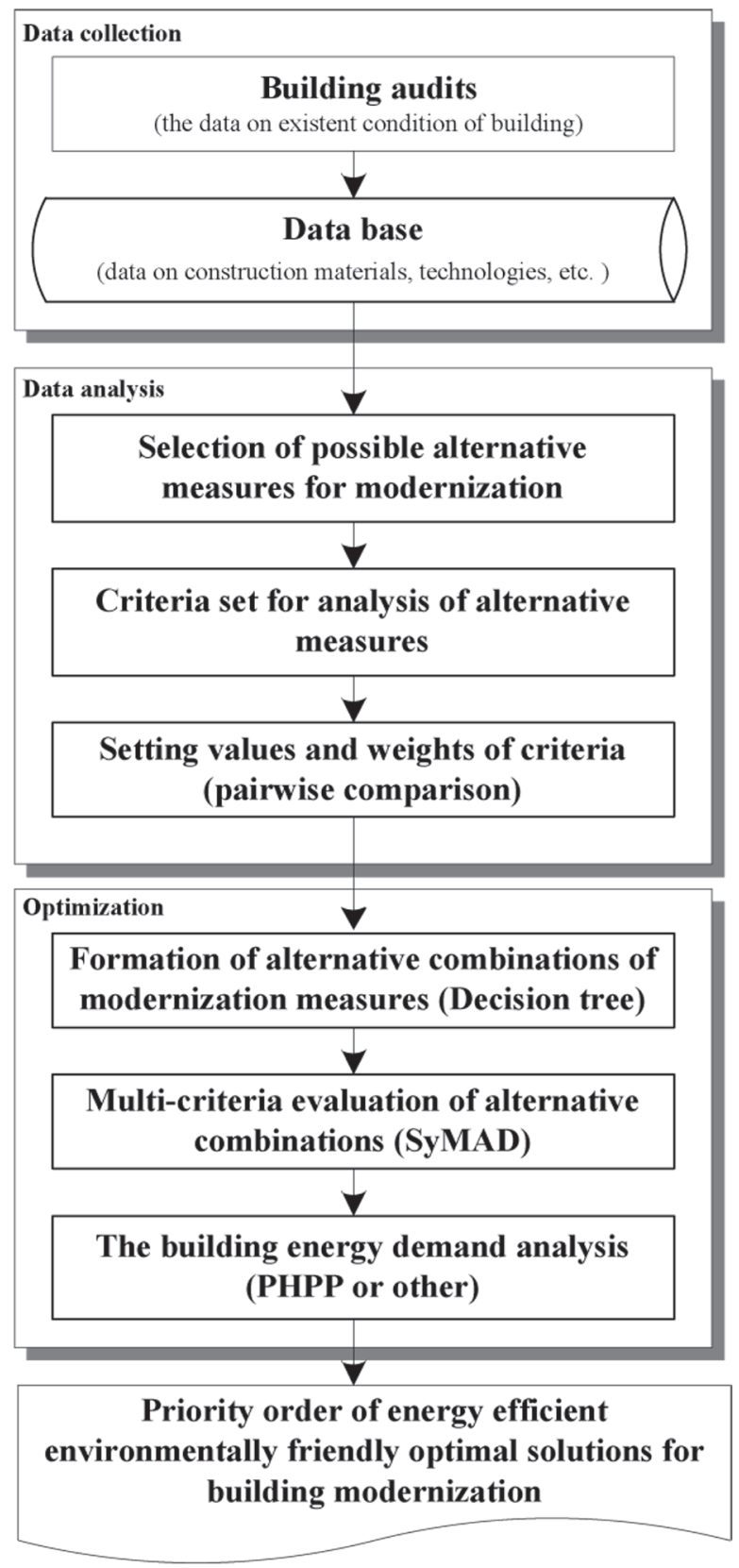

Fig. 1. The proposed decision model 
nologies, etc. After that, the experts select possible alternative measures for modernization taking into account the result of building energy audit, the state of building structures and specific problems found in exact building.

Experts together with building managers determine the criteria set for analysis of alternative modernization measures. On next step the experts, using pairwise comparison set the values and weights of criteria. Formation of alternative combinations of modernization measures were made with help of decision tree model (Fig. 2). This

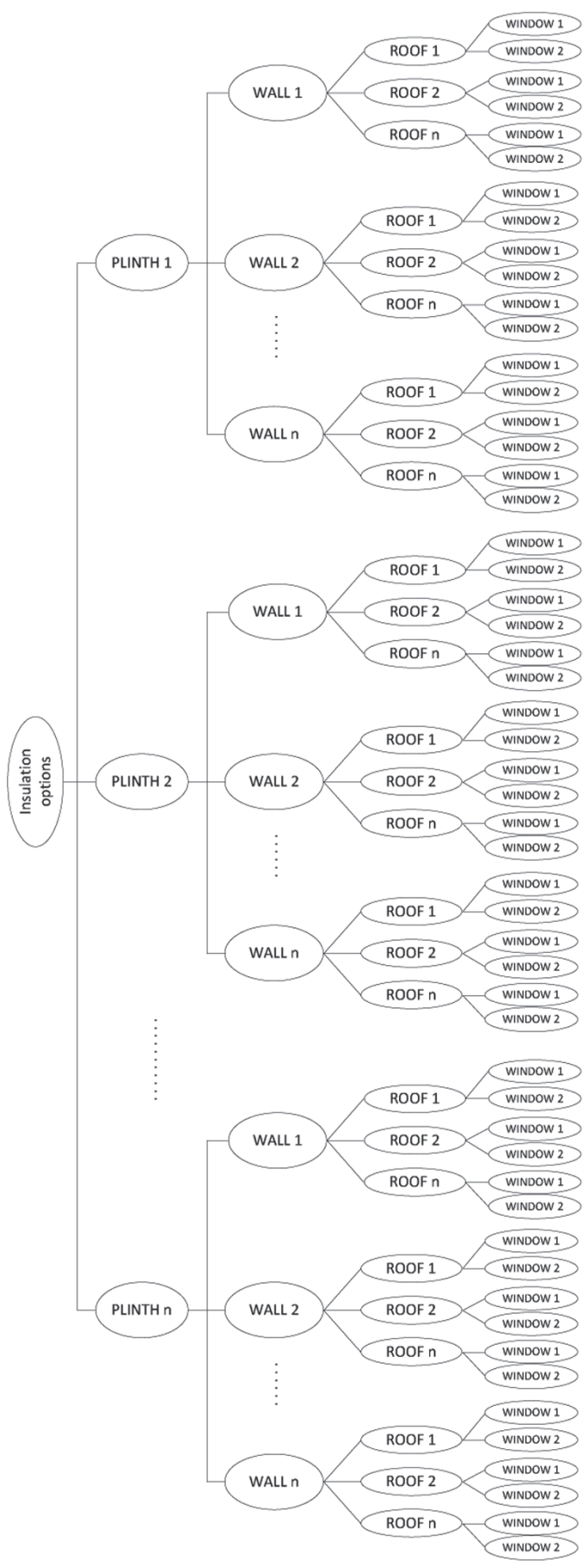

Fig. 2. A fragment of decision tree used for selection of alternative combinations of modernization measures model identifies the combinations of insulation options for the plinth, walls and roof. Several options can be used in combination with each other. Multi-criteria evaluation of alternative combinations authors propose to perform by using SyMAD-3 method, as it belongs to the group of synthesis methods and enables step-by-step selection of the most effective option from a generated set of alternatives. Decision tree generates many alternative combinations. To minimize the computing routine the analysis of building energy demand is performing for several alternatives from the priority order list. The analysis of building energy demand shows how the alternative combinations of modernization measures influence the energy consumption in exact building. Decision-maker selects the best performing alternative in terms of energy consumption, cost of instalment and other relevant criteria.

\section{The set of criteria}

Factors determining the necessity of public buildings refurbishment are related to the problems encountered in particular building. Although the problems are unique to a particular case, the studies show often encountered ones: indoor temperature is too low or too high, the floor temperature is too low, relative humidity is too low or too high, indoor airflow is too high, carbon dioxide concentration in premises is too high, high energy consumption for heating, hot water and electricity production, high physical depreciation of building constructions, windows, doors, engineering systems, poor building external appearance. The criteria selected for the evaluation of public building modernization measures are defined in Table 1 .

Setting the values and weights of criteria. The weights of criteria are determined using pairwise comparison. Numerical values of subjective criteria weights $\bar{q}_{j}(j=\overline{1, n)}$ are determined by solving optimization task:

$$
\min \left\{\sum_{i=1}^{n} \sum_{j=1}^{n}\left(b_{i j} \bar{q}_{j}-\bar{q}_{i}\right)^{2}\right\},
$$

Table 1. Criteria set for analysis of alternative modernization measures

\begin{tabular}{lll}
\hline No & \multicolumn{1}{c}{ Criteria } & \multicolumn{1}{c}{ Measuring units } \\
\hline$R_{1}$ & Heat transfer coefficient & $\mathrm{W} / \mathrm{m}^{2} \mathrm{~K}$ \\
$R_{2}$ & The cost of measure & EUR \\
$R_{3}$ & Predicted lifespan of the measure & years \\
$R_{4}$ & $\begin{array}{l}\text { Construction work possibility not } \\
\text { depending on the seasonality }\end{array}$ & points \\
$R_{5}$ & Annual savings & $\mathrm{kWh} / \mathrm{m}^{2} / \mathrm{m}$ \\
$R_{6}$ & Simple payback period & years \\
$R_{7}$ & Thickness of structure* & $\mathrm{mm}$ \\
\hline
\end{tabular}

Note: * only for plinth, exterior walls and roof. 
here $b_{i j}$ is the pairwise comparison of criteria $R_{i}$ and $R_{j}$ $(i, j=\overline{1, n})$ made by experts. This indicator is the ratio of experts' ratings of the $i^{\text {th }}$ and $j^{\text {th }}$ criteria:

$$
b_{i j}=\frac{\bar{q}_{i}}{\bar{q}_{j}} .
$$

The information collected was systematized using pairwise comparison matrices and the weights for each building constructional part were set after the calculations were made and the criteria are ranked. The results are shown in Table 3. A sufficient compatibility has been established, so the further calculations can be performed.

\section{SyMAD-3 the synthesis method of modernization decisions for the building envelope}

Decision-making is the process of defining the goals, determining possible alternatives, gathering information about relevant criteria and selecting the optimal alternatives. Making decision on basis of one criterion is unreliable, as real world problems are usually complicated due to diverse information on object under consideration and often conflicting aims of decision-makers. Finding the right decision for a complicated problem could be the challenge if appropriate tools are absent. There is opinion, that each model can be evaluated with help of multiple criteria methodology and, therefore, results could be more helpful and practical (Zolfani et al. 2015). In this article the authors are applying a new multistage method: Synthesis of Multiple Attribute Decisions by three methods - SyMAD-3 (Simanaviciene et al. 2012). This method is addressed to combine multiple criteria decisions into a single solution. Authors believe this method is very suitable for evaluation of modernization decisions of the building envelope. The presented algorithm comprises method for integrated significance determination of efficiency indicators and multiple criteria decision methods COPRAS (Zavadskas, Kaklauskas 1996), TOPSIS (Yoon, Hwang 1981) and $S A W$ (Churchman, Ackoff 1954). Three multiple criteria decision support methods based on quantitative measurements used to increase the reliability of the decision.

A multiple criteria complex proportional assessment of the projects method (COPRAS) (Zavadskas et al. 2004; Kaklauskas et al. 2005). The significance and priority, examined using this method, directly and proportionally depends on the system of criteria that adequately characterizes the alternatives, efficiency indicators' values and their weights'. The experts determine the system of criteria and calculate the criteria values and the initial significances. The groups of interest (customer, consumer, etc.) according to their goals and opportunities may adjust all this information. Therefore, alternative assessment results provide a detailed outline of the general original data of the experts and groups of interest:

$$
Q_{i}=S_{+i}+\frac{S_{-\min } \cdot \sum_{i=1}^{m} S_{-i}}{S_{-i} \cdot \sum_{i=1}^{m} \frac{S_{-\min }}{S_{-i}}}, i=\overline{1, m} .
$$

The relative significance of the comparative options (efficiency) is determined by characterizing positive (project "plus") $S_{+i}$ and negative (project "minus") $S_{-i}$ features. The higher the $Q_{i}$, the higher the project efficiency (prioritizing).

Technique for Order Preference by Similarity to Ideal Solution method (TOPSIS). Yoon and Hwang (1981) developed the methodology based on the concept that the optimal alternative is at the minimum distance to the ideal solution and the greatest distance to the worst solution. This method is called the Technique for Order Preference by similarity to Ideal Solution method (TOPSIS). The relative distance of each $(i)$ option to the ideal is determined:

$$
K_{i}=\frac{L_{i}^{-}}{L_{i}^{+}+L_{i}^{-}}, \quad i=\overline{1, m}, \quad \text { kai } \quad K_{i} \in[0 ; 1],
$$

here $L_{i}^{+}$is the distance between the comparative $(i)$ and the ideal option. $L_{i}^{-}$is the distance between the comparative $(i)$ and the worst option. The closer the $K_{i}$ value is to 1 , the closer the $(i)$ option is to $a^{+}$, i.e. rational option will be the one that $K_{i}$ value is the highest.

Simple Additive Weighting (SAW) method. Simple additive weighting (SAW) is well known, the most simple and most widely applied. MacCrimmon (1968) presented principle rules of this method. The normalized values are multiplied by significances and summed when determining the rationality of the option. The maximum sum of products shows the rational option:

$$
A=\left\{A_{i} \mid \max _{i} \sum_{j=1}^{n} \bar{q}_{j} \bar{x}_{i j} / \sum_{j=1}^{n} \bar{q}_{j}\right\},
$$

here $\bar{x}_{i j}$ is normalized decision matrix.

The SyMAD-3 method. The purpose of this method is multi- objective decision synthesis by using three multiple criteria decision methods (Simanaviciene et al. 2012, 2014). The multistage decision tree model (Fig. 2) represents the structure used for analysis of alternative solutions being on different stages of decision making process. The model represents a decision tree and uses the following notations:

- $K=\{k\},(k=1,2, \ldots, c)$ is the set of stages in the decision analysis, $k$ is the stage number; $c$ is the number of stages;

- $m_{k}(k=1,2,3)$ is the number of decision tree nodes in each stage, determined depending on the number of the decision tables;

$-z=m c$ is the number of decision tree branches connecting the root node with the terminal node (leaf node), where $m c$ is the number of the last decision 
tree branches. Number of the branches is the number of the alternative combinations.

By using the decision tree model and the required initial data the analysed alternatives can be grouped and ranked by selecting the appropriate algorithm. The algorithm of SyMAD-3 method consists of two stages.

Stage 1 is used to determine the object, the primary effectiveness of alternatives and to set the calculation data. There are six steps on this stage:

1. Determining the number of solution stages and creating a system of efficiency criteria for each stage $k$ of the solution. $K=\{k\},(k=1,2, \ldots, c)$ is the set of stages in the decision analysis, $k$ is the stage number, $c$ is the number of stages. In addition, decision tables for each stage of the solution are made, where $m_{k}$ is the number of decision tree nodes in each stage at the $k$ stage determined depending on the number of the decision tables. Using these data tables, decision matrices are constructed:

$$
X_{t}=\left[x_{i j}^{t}\right], t=\overline{1, m} ; i=\overline{1, a_{t}} ; j=\overline{1, n_{k}},
$$

here $t$ is the number of the decision tables, $a_{t}$ is the number of alternatives in the $t$ decision table and $n_{k}$ is the number of the efficiency criteria at the $k$ stage.

2. Filling the matrices of pairwise comparison, used to determine the significance of efficiency criteria:

$$
E=\{p\}, p=1,2, \ldots, e_{p}
$$

here $E$ is the group of experts, $p$ - the expert number, $e_{p}-$ the total number of experts.

3. Setting the coherence of the pairwise comparison.

The degree of compatibility $S$ is calculated for every matrix:

$$
S=\frac{S_{I}}{S_{A}}
$$

here $S_{I}$ is the matrix compatibility index, $S_{A}$ is average of the random index. If $S<0.1$ matrix compatibility is sufficient and matrix is used to determine the significance, if not, matrix data are not used for further calculations (Saaty 1994).
4. Determining the significance of criteria for the $k$ stage. The values of integrated significance $\bar{q}_{k j}$, $j=\overline{1, n}, k=\overline{1, c}$ are calculated using the matrixes of pairwise comparison filled by experts and processed using the method of least squares. The compatibility of experts' opinions on the significance of criteria is checked by calculating the coefficient of concordance. If the compatibility of experts' opinions is sufficient, the integrated significance $q_{k j}^{*}$, $j=\overline{1, n}_{k}, k=\overline{1, c}$ are calculating. If the expert opinions' compatibility is insufficient, experts' group composition is reconsidered. The calculations are repeated with the data obtained from renewed expert group.

5. The rationality of alternatives is being determined by three methods: TOPSIS, SAW, COPRAS, using the earlier formed decision matrixes $X_{t}=\left[x_{j}^{t}\right], t=\overline{1, m} ; i=\overline{1, a_{t}} ; j=\overline{1, n_{k}}$ and values of integrated significance $q_{k j}^{*}, j=\overline{1, n}_{k}, k=\overline{1, c}$.

6. After performing the calculations by all three methods, the results are presented in the form of relative importance:

$$
\begin{gathered}
\left(A_{k}^{i}[\text { TOPSIS }, S A W, C O P R A S]\right)=\left(R_{k T}^{i}, R_{k S}^{i}, R_{k C}^{i}\right), \\
k=\overline{1, c}, i=\overline{1, m_{k}} .
\end{gathered}
$$

Stage 2 is used to form the alternative combinations and evaluate their rationality. The alternative combinations $B_{s}, s=\overline{1, z}$ are created from the alternatives composed at the first stage using the decision tree model and presented in decision tables $A_{k}$. This stage consists of the following three steps:

1. Alternative combinations can be presented as a vector:

$$
\begin{aligned}
& B_{s}=\left\{\left(R_{1, T}^{i}, R_{1, S}^{i}, R_{1, C}^{i}\right), \ldots,\left(R_{c, T}^{i}, R_{c, S}^{i}, R_{c, C}^{i}\right) \mid\right. \\
& \left.i=\overline{1, m_{k}}, k=\overline{1, c}\right\}, s=\overline{1, z} .
\end{aligned}
$$

\begin{tabular}{|c|c|c|c|c|c|c|c|c|c|}
\hline Stages & \multicolumn{3}{|c|}{ I stage } & \multicolumn{3}{|c|}{$\ldots$} & \multicolumn{3}{|c|}{$c$ stage } \\
\hline Alternatives $\quad$ Criteria & $\mathrm{R}_{[1]}$ & $\mathrm{R}_{[2]}$ & $\mathrm{R}_{[3]}$ & $\ldots$ & $\ldots$ & $\ldots$ & $\mathrm{R}_{[7]}$ & $\mathrm{R}_{[8]}$ & $\mathrm{R}_{[9]}$ \\
\hline$B_{1}$ & $R_{c, T}^{1}$ & $R_{c, S}^{1}$ & $R_{c, C}^{1}$ & $\ldots$ & $\ldots$ & $\ldots$ & $R_{S, T}^{1}$ & $R_{s, S}^{1}$ & $R_{s, C}^{1}$ \\
\hline$B_{2}$ & $R_{c, T}^{1}$ & $R_{c, S}^{1}$ & $R_{c, C}^{1}$ & $\ldots$ & $\ldots$ & $\ldots$ & $R_{S, T}^{2}$ & $R_{S, S}^{2}$ & $R_{S, C}^{2}$ \\
\hline$\ldots$ & $\ldots$ & $\ldots$ & $\ldots$ & $\ldots$ & $\ldots$ & $\ldots$ & $\ldots$ & $\ldots$ & $\ldots$ \\
\hline$B_{\mathrm{z}}$ & $R_{c, T}^{n 1}$ & $R_{c, S}^{n 1}$ & $R_{c, C}^{n 1}$ & $\ldots$ & $\ldots$ & $\ldots$ & $R_{S, T}^{n 3}$ & $R_{S, S}^{n 3}$ & $R_{s, C}^{n 3}$ \\
\hline Optimality direction & $\operatorname{Max}$ & $\operatorname{Max}$ & $\operatorname{Max}$ & $\ldots$ & $\ldots$ & $\ldots$ & $\operatorname{Max}$ & $\operatorname{Max}$ & $\operatorname{Max}$ \\
\hline
\end{tabular}

2. The obtained alternative combinations are recorded into decision table (Table 2) and this data will be used for further calculations.

Table 2. Decision table for alternative combinations of modernization measures 
3. Each alternative combination is evaluated by the TOPSIS, SAW and COPRAS methods. Using the data from the decision table (Table 2) the decision matrix is being compiled:

$$
Y=\left[y_{s l}\right], s=\overline{1, z}, l=\overline{1, k \times m t},
$$

here $m t$ is the number of the used methods (in our case $m t=3), k$ - stage number, $(k=1,2, \ldots, c)$. In this case $s$ is the number of the rows of $Y$ matrix, $l$-number of the columns of $Y$ matrix:

$$
\begin{aligned}
& \left(y_{s l}\right)=\left(R_{k, M r}^{i}\right), \\
& s=\overline{1, z}, l=\overline{1, k \times t}, i=\overline{1, m_{k}}, k=\overline{1, c}, M_{r}=\overline{1, t},
\end{aligned}
$$

here $M_{r}$ is the number of the used methods.

A set of criteria $R=\left\{R_{l}\right\}, l=1,2, \ldots, k \times m t$ required to evaluate the alternatives presented in the matrix $Y$ is made. The optimal value of these criteria are maximum and their significance values are the same, since they are affected neither by subjective nor objective factors. The significance values of criteria have to satisfy the following condition:

$$
\sum_{l=1}^{k \times m t} w_{l}=1
$$

here $k$ is the number of stages and $m t$ is the number of methods.

After evaluating the effectiveness of the alternative combinations by each of above mentioned methods, their values and ranks are presented in a table.

The described method can be used for various multistage, multi- objective decision-making challenges where information on alternatives is given in the quantitative form. In this case, the SyMAD-3 method is used for the analysis and synthesis of replacement solutions for external walls, roof, plinth insulation and windows.

\section{Case study}

\subsection{Description of the object}

The building of Vaidotai railway station was built in 1980. It has $2,168.00 \mathrm{~m}^{2}$ of total area and the five floors. The heating of building was provided by a local gas boiler located in the basement. The roof is superposed, covered with the membrane. The existing roof structure formed from aerated concrete $200 \mathrm{~mm}$ on the reinforced concrete floor slab. The building exterior walls are built of $510 \mathrm{~mm}$ silicate bricks, inside surface is plastered and painted. Building audit determined the $25 \%$ physical depreciation of building. The finishing of the walls and ceilings is worn out. The facade has visible cracks of 1.0 $1.4 \mathrm{~mm}$. The ventilation chimneys' tinning is worn out. Mechanical condition of the floors and the foundation is satisfactory. The basement aboveground wall (plinth) is constructed of $400 \mathrm{~mm}$ thick reinforced concrete blocks. The finishing of plinth is in several places crumbled, has visible cracks of $0.7-0.9 \mathrm{~mm}$. Building experts recom- mended to install the heat insulating layer and a rolled covering on the roof during the repair works. The tinning works of the worn out chimneys must be performed. The building examination showed that the structural condition of the exterior walls of the building is in satisfactory condition. It is recommended to restore the masonry walls and parapet tinning, to install the insulation and the exterior finishing layer. It is also proposed to insulate the plinth and to install the exterior finishing layer. Experts recommended replacement of the windows and doors.

\subsection{Data analysis and optimization}

Possible modernization measures were considered taking into account the results of building audit and recommendations provided by experts. The multistage decision model is compiled, taking into account the basement aboveground wall (plinth), exterior walls and roof insulation options. Four insulation options for each element were considered. Two replacement options for windows were selected.

All modernization measures (the plinth, walls and roof) are characterized by the equal set of criteria. All alternative combinations of plinths, walls and roofs were assessed taking into account those criteria. The values of criteria characterizing the alternative measures are presented in Table 3.

At the beginning, alternative measures were evaluated separately, using the TOPSIS, SAW and COPRAS methods. Then the results were moved into new decision matrix and the evaluation of alternative combinations of modernization measures is performed using same methods. Intermediate results, obtained after the first iteration by applying the calculation algorithm, are presented in Table 4 . The 64 alternative combinations of measures were comprised on the basis of intermediate results (Table 5). Calculation results show that the rational combination is B38, which consists of $3^{\text {rd }}$ plinth, $2^{\text {nd }}$ wall and $2^{\text {nd }}$ roof options.

\subsection{The building energy demand analysis}

Taking into account the above presented roof, walls and plinth insulation decisions and in order to achieve characteristics of the low energy building, the building engineering systems were analysed additionally. These calculations are carried out using the Passive House Planning Package, hereinafter - PHPP.

As air infiltration is relatively small in airtight low energy building, a mechanical ventilation system should be installed, in order to ensure comfortable indoor conditions. The most important part of the ventilation system is an exchanger with the efficiency ratio not less than 0.8. So the ventilation system with heat recovery was considered with the efficiency of at least 0.8 and the ventilation system fan power use shall less than $0.75 \mathrm{Wh} / \mathrm{m}^{3}$. The building tightness should not exceed $0.6 \mathrm{~h}^{-1}$, so for the building to meet the low energy building standard the $0.52 \mathrm{~h}^{-1}$ value is accepted. 
Table 3. Alternative measures and values of criteria

\begin{tabular}{|c|c|c|c|c|c|c|c|}
\hline \multirow{2}{*}{$\begin{array}{c}\text { Alternative } \\
\text { measures }\end{array}$} & \multicolumn{7}{|c|}{ Criteria } \\
\hline & $R_{1}$ & $R_{2}$ & $R_{3}$ & $R_{4}$ & $R_{5}$ & $R_{6}$ & $R_{7}$ \\
\hline 1 & 2 & 3 & 4 & 5 & 6 & 7 & 8 \\
\hline Plinth 1 & 0.18 & $9,155.17$ & 30 & 2 & 3.00 & 12 & 600 \\
\hline Plinth 2 & 0.16 & $9,408.31$ & 25 & 2 & 3.66 & 12 & 630 \\
\hline Plinth 3 & 0,14 & $9,745.72$ & 27 & 6 & 3.78 & 15 & 670 \\
\hline Plinth 4 & 0,12 & $10,167.40$ & 25 & 2 & 3.89 & 14 & 720 \\
\hline Wall 1 & 0.15 & $104,699.95$ & 25 & 3 & 58.80 & 12 & 690 \\
\hline Wall 2 & 0.14 & $107,155.06$ & 26 & 4 & 59.75 & 12 & 710 \\
\hline Wall 3 & 0.11 & $122,949.49$ & 27 & 6 & 62.59 & 15 & 780 \\
\hline Wall 4 & 0.10 & $141,751.33$ & 25 & 3 & 63.54 & 13 & 820 \\
\hline Roof 1 & 0.12 & $31,511.24$ & 25 & 6 & 33.05 & 17 & 520 \\
\hline Roof 2 & 0.11 & $33,008.28$ & 25 & 5 & 33.30 & 17 & 540 \\
\hline Roof 3 & 0.10 & $34,520.68$ & 25 & 4 & 33.54 & 22 & 590 \\
\hline Roof 4 & 0.09 & $35,744.03$ & 25 & 6 & 33.78 & 20 & 620 \\
\hline Window 1 & 1.0 & $87,197.21$ & 25 & 5 & 42.91 & 14 & - \\
\hline Window 2 & 0.7 & $104,635.98$ & 28 & 5 & 50.23 & 14 & - \\
\hline $\operatorname{Min} / \max$ & $\min$ & $\min$ & $\max$ & $\max$ & $\max$ & $\min$ & $\min$ \\
\hline \multicolumn{8}{|c|}{ Significance of criteria } \\
\hline Plinth & 0.121 & 0.254 & 0.151 & 0.046 & 0.173 & 0.175 & 0.080 \\
\hline Wall & 0.140 & 0.245 & 0.136 & 0.047 & 0.162 & 0.172 & 0.097 \\
\hline Roof & 0.136 & 0.260 & 0.132 & 0.049 & 0.155 & 0.216 & 0.052 \\
\hline Windows & 0.147 & 0.253 & 0.131 & 0.052 & 0.209 & 0.208 & - \\
\hline
\end{tabular}

Table 4. The significance of the alternatives and ranks obtained using TOPSIS, SAW and COPRAS methods

\begin{tabular}{c|cccccc}
\hline \multirow{2}{*}{ Mlternatives } & \multicolumn{3}{|c}{ Rationality } & \multicolumn{3}{c}{ Rank } \\
\cline { 2 - 7 } & TOPSIS & SAW & COPRAS & TOPSIS & SAW & COPRAS \\
\hline Plinth 1 & 0.395 & 0.876 & 0.243 & 4 & 4 & 4 \\
Plinth 2 & 0.447 & 0.887 & 0.248 & 3 & 3 & 3 \\
Plinth 3 & 0.604 & 0.907 & 0.260 & 1 & 1 & 1 \\
Plinth 4 & 0.486 & 0.894 & 0.249 & 2 & 2 & 2 \\
\hline Wall 1 & 0.550 & 0.892 & 0.246 & 3 & 3 & 3 \\
Wall 2 & 0.609 & 0.910 & 0.253 & 1 & 1 & 2 \\
Wall 3 & 0.557 & 0.909 & 0.255 & 2 & 2 & 1 \\
Wall 4 & 0.434 & 0.889 & 0.245 & 4 & 4 & 4 \\
\hline Roof 1 & 0.629 & 0.954 & 0.255 & 2 & 1 & 1 \\
Roof 2 & 0.671 & 0.946 & 0.254 & 1 & 2 & 2 \\
Roof 3 & 0.303 & 0.895 & 0.239 & 4 & 4 & 4 \\
Roof 4 & 0.512 & 0.937 & 0.251 & 3 & 3 & 3 \\
\hline Window 1 & 0.423 & 0.911 & 0.487 & 2 & 2 & 2 \\
Window 2 & 0.577 & 0.958 & 0.513 & 1 & 1 & 1 \\
\hline
\end{tabular}

Additional measures reducing the overheating of the building in the summer time were considered. The $19.2 \%$ probability that the indoor temperature to be higher than $+25^{\circ} \mathrm{C}$ in summer is obtained assessing all the input data. This problem can be solved by installing the blinds on the eastern, southern and western windows that would cover $50 \%$ of the glazing.

The heating system pipeline design features, as well as the temperature of the rooms, through which these pipelines run, and other data are entered. The heating system and water pipeline heat losses were calculated.
The condensing gas boiler of $85 \mathrm{~kW}$ capacity, which will provide hot water and will perform additional functions of the heating system, was selected at the building owner's request.

The quantity of electrical appliances is counted: lamps, office equipment and other devices. Taking into account the purpose of the premises the comfortable lighting is selected.

The initial data was entered into input data window (Fig. 3). 
Table 5. Fragment of the alternative combinations of modernization measures

\begin{tabular}{|c|c|c|c|c|c|c|c|c|c|}
\hline Building element & \multicolumn{3}{|c|}{ Plinth } & \multicolumn{3}{|c|}{ Wall } & \multicolumn{3}{|c|}{ Roof } \\
\hline $\begin{array}{l}\text { Alternative } \\
\text { combination }\end{array}$ & $R_{[1]}^{T}$ & $R_{[2]}^{S}$ & $R_{[3]}^{C}$ & $R_{[4]}^{T}$ & $R_{[5]}^{S_{[5]}}$ & $R_{[6]}^{C}$ & $R_{[7]}^{T}$ & $R_{[8]}^{S}$ & $R_{[9]}^{C}$ \\
\hline$B^{1}$ & 0.395 & 0.876 & 0.243 & 0.554 & 0.892 & 0.246 & 0.629 & 0.954 & 0.255 \\
\hline$B^{2}$ & 0.395 & 0.876 & 0.243 & 0.554 & 0.892 & 0.246 & 0.671 & 0.946 & 0.254 \\
\hline$B^{3}$ & 0.395 & 0.876 & 0.243 & 0.554 & 0.892 & 0.246 & 0.303 & 0.895 & 0.239 \\
\hline$B^{4}$ & 0.395 & 0.876 & 0.243 & 0.554 & 0.892 & 0.246 & 0.512 & 0.937 & 0.251 \\
\hline$B^{5}$ & 0.395 & 0.876 & 0.243 & 0.609 & 0.910 & 0.253 & 0.629 & 0.954 & 0.255 \\
\hline$B^{6}$ & 0.395 & 0.876 & 0.243 & 0.609 & 0.910 & 0.253 & 0.671 & 0.946 & 0.254 \\
\hline $\begin{array}{c}\ldots \ldots \\
B^{35}\end{array}$ & $\begin{array}{c}\cdots . \\
0.604\end{array}$ & 0.907 & $\begin{array}{c}\ldots \ldots \\
0.260\end{array}$ & $\begin{array}{c}\ldots \ldots \\
0.554\end{array}$ & 0.892 & 0.246 & $\begin{array}{c}\ldots . . \\
0.303\end{array}$ & $\begin{array}{c}\ldots \ldots \\
0.895\end{array}$ & $\begin{array}{c}\cdots . . \\
0.239\end{array}$ \\
\hline$B^{36}$ & 0.604 & 0.907 & 0.260 & 0.554 & 0.892 & 0.246 & 0.512 & 0.937 & 0.251 \\
\hline$B^{37}$ & 0.604 & 0.907 & 0.260 & 0.609 & 0.910 & 0.253 & 0.629 & 0.954 & 0.255 \\
\hline$B^{38}$ & 0.604 & 0.907 & 0.260 & 0.609 & 0.910 & 0.253 & 0.671 & 0.946 & 0.254 \\
\hline$B^{39}$ & 0.604 & 0.907 & 0.260 & 0.609 & 0.910 & 0.253 & 0.303 & 0.895 & 0.239 \\
\hline$B^{40}$ & 0.604 & 0.907 & 0.260 & 0.609 & 0.910 & 0.253 & 0.512 & 0.937 & 0.251 \\
\hline $\begin{array}{l}\ldots \ldots \\
B^{63}\end{array}$ & $\begin{array}{c}\ldots \ldots \\
0.486\end{array}$ & $\begin{array}{c}\cdots \cdots \\
0.894\end{array}$ & $\begin{array}{c}\ldots \ldots \\
0.249\end{array}$ & $\begin{array}{c}\ldots \ldots \\
0.434\end{array}$ & 0.889 & 0.245 & $\begin{array}{c}\ldots \ldots \\
0.303\end{array}$ & $\begin{array}{c}\ldots \ldots \\
0.895\end{array}$ & $\begin{array}{c}\cdots . . \\
0.239\end{array}$ \\
\hline$B^{64}$ & 0.486 & 0.894 & 0.249 & 0.434 & 0.889 & 0.245 & 0.512 & 0.937 & 0.251 \\
\hline Optimality direction & Max & Max & Max & Max & Max & Max & Max & Max & Max \\
\hline Significance & 0.111 & 0.111 & 0.111 & 0.111 & 0.111 & 0.111 & 0.111 & 0.111 & 0.111 \\
\hline
\end{tabular}

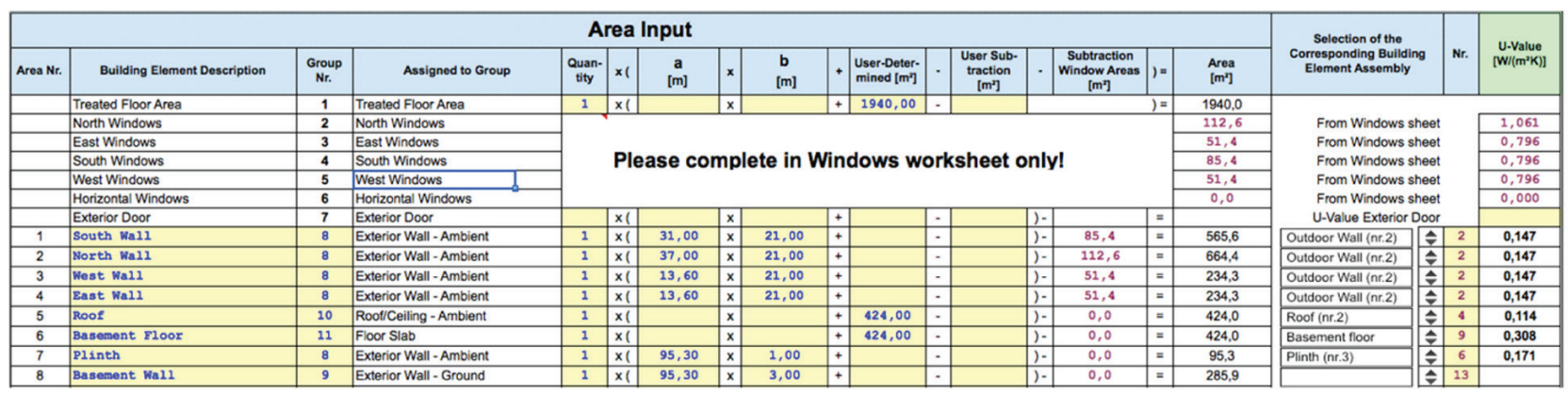

Fig. 3. Input data window

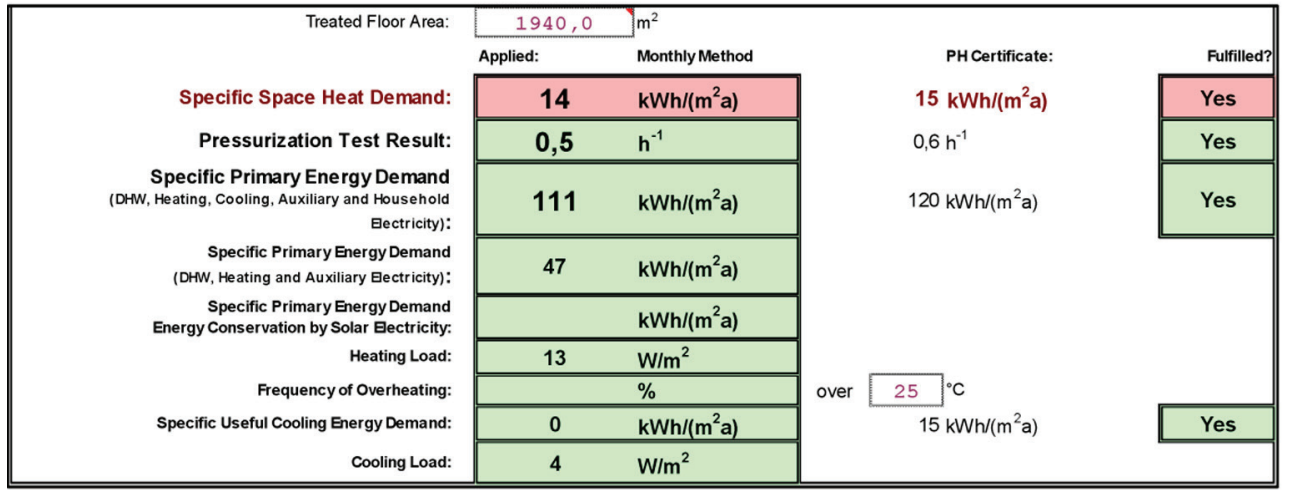

Fig. 4. Evaluation of the building energy demand using the PHPP program

The program calculates all the energy used in the building. It is also applies a certain rate for each different type of energy and recalculate the actual amount of energy into primary annual energy demand.

Finally, the energy demand for space heating is obtained and assessed whether the foreseen modernization measures allow reaching the characteristics of the low energy building. Final evaluation of the selected building modernization measures using the PHPP program is shown in Figure 4. 


\section{Conclusions}

The aim of our study was to present the decision model for selection of optimal combinations of modernization measures. To analyse the building modernization measures and to form all possible combinations of these measures the decision tree model was applied. The presented algorithm of decision synthesis method comprises method for integrated significance determination of efficiency indicators and multiple criteria decision methods. Three multiple criteria decision support methods based on quantitative measurements used to increase the reliability of the decision.

This study has some limitations that should be pointed out. Decision tree generates many alternative combinations. To minimize the computing routine the analysis of building energy demand was performed at the final stage of analysis and only for several alternatives from the priority order list received after assessment of so called "passive" modernization measures (insulation solutions for building envelope and windows replacement). The analysis of possible alternative building engineering systems was not included in our case study. The only one of accordingly ventilation, heating, cooling and shading systems was considered for all combinations. As such, future research could consider the inclusion of different alternatives of building engineering systems and extension of decision model with new subsystems enabling the fast processing of big data. Such analysis will show more precisely how the alternative combinations of "passive" modernization measures together with "active" measures influence the energy consumption in exact building.

Despite these limitations, our study makes some important contributions to existing research. Our results show that methods of synthesis, like SyMAD-3 method, could be successfully applied for step-by-step selection of the most effective option from a generated set of alternatives. The SyMAD-3 method can be used for various multistage, multi-objective decision-making challenges where information on alternatives is given in the quantitative form. Our results also have some implications for building owners and building managers. Authors believe that this method is very suitable for evaluation of modernization decisions of the building and enables decision-maker to select the best performing alternative in terms of energy consumption, cost of instalment and other relevant criteria.

The successful creation of sustainable building, infrastructure systems and environmentally conscious designs requires a holistic, integrated, and multidisciplinary approach. Therefore, the special emphasis should be given to collaborative approaches. In the building design, operation and maintenance, and especially in the modernization processes, the cooperation of architects, engineers and experts of construction technology is very important.

\section{References}

Aja, A. H.; Parellada, A. M.; Rodriguez-Suarez, I.; Madruga, C. G. 2015. Evolution of urban renewal policies in areas of integrated renovation in Spain (1978-2012), Informes De La Construccion 67(EXTRA-1): m024.

Bayulken, B.; Huisingh, D. 2015. A literature review of historical trends and emerging theoretical approaches for developing sustainable cities (part 1), Journal of Cleaner Production. In Press, Corrected Proof. http://dx.doi.org/10.1016/j.jclepro.2014.12.100

Bucoń, R.; Sobotka, A. 2015. Decision-making model for choosing residential building repair variants, Journal of Civil Engineering and Management 21(7): 893-901. http://dx.doi.org/10.3846/13923730.2014.895411

Churchman, C. W.; Ackoff, R. L. 1954. An approximate measure of value, Journal of Operations Research Society of America 2(2): 172-187. http://dx.doi.org/10.1287/opre.2.2.172

Directive 2010/31/EU on the Energy Performance of Buildings (EPBD). 2010. The European Parliament and the Council of the EU, 19 May 2010, Official Journal of the European Communities 2010: L153/13-35.

Dzeng, R.-J.; Wang, W.-C.; Hsiao, F.-Y. 2015. Function-space assignment and movement simulation model for building renovation, Journal of Civil Engineering and Management 21(5): $578-590$.

http://dx.doi.org/10.3846/13923730.2014.890652

Friege, J.; Chappin, E. 2014. Modelling decisions on energyefficient renovations: a review, Renewable \& Sustainable Energy Reviews 39: 196-208. http://dx.doi.org/10.1016/j.rser.2014.07.091

Gimenez, C.; Sierra, V.; Rodon, J. 2012. Sustainable operations: their impact on the triple bottom line, International Journal of Production Economics 140(1): 149-159. http://dx.doi.org/10.1016/j.ijpe.2012.01.035

Ham, Y.; Golparvar-Fard, M. 2015. Mapping actual thermal properties to building elements in gbXML-based BIM for reliable building energy performance modeling, Automation in Construction 49: 214-224. http://dx.doi.org/10.1016/j.autcon.2014.07.009

International Energy Agency (IEA). 2013. Transition to sustainable buildings. Strategies and opportunities to 2050 [online], [cited 10 September 2015]. Available from Internet: http://www.iea.org/Textbase/npsum/building2013SUM.pdf

Kaklauskas, A.; Zavadskas, E. K.; Raslanas, S. 2005. Multivariant design and multiple criteria analysis of building refurbishments, Energy and Buildings 37(4): 361-372. http://dx.doi.org/10.1016/j.enbuild.2004.07.005

Kang, H. J. 2015. Development of a systematic model for an assessment too for sustainable buildings based on a structural framework, Energy and Buildings 104: 287-301. http://dx.doi.org/10.1016/j.enbuild.2015.07.015

Kim, Y.-B.; Lee, S.-Y.; Jeong, B.-R. 2009. Analysis of the insulation effectiveness of the thermal insulator by the installation methods, Protected Horticulture and Plant Factory 18(4): 332-340.

Lombera, J.-T. S.-J.; Rojo, J. C. 2010. Industrial building design stage based on a system approach to their environmental sustainability, Construction and Building Materials 24(4): $438-447$. http://dx.doi.org/10.1016/j.conbuildmat.2009.10.019

MacCrimmon, K. R. 1968. Decision marking among multiple-attribute alternatives: a survey and consolidated approach. RAND Memorandum, RM-4823-ARPA. 63 p.

Mahdavi, A.; Tahmasebi, F. 2015. Predicting people's presence in buildings: an empirically based model performance analysis, Energy and Buildings 86: 349-355. http://dx.doi.org/10.1016/j.enbuild.2014.10.027 
Martinaitis, V.; Zavadskas, E. K.; Motuzienè, V.; Vilutienè, T. 2015. Importance of occupancy information when simulating energy demand of energy efficient house: a case study, Energy and Buildings 101: 64-75. http://dx.doi.org/10.1016/j.enbuild.2015.04.031

Medineckiene, M.; Zavadskas, E. K.; Bjork, F.; Turskis, Z. 2015. Multi-criteria decision-making system for sustainable building assessment/certification, Archives of Civil and Mechanical Engineering 15(1): 11-18. http://dx.doi.org/10.1016/j.acme.2014.09.001

Mjoernell, K.; Boss, A.; Lindahl, M.; Molnar, S. 2014. A tool to evaluate different renovation alternatives with regard to sustainability, Sustainability 6(7): 4227-4245. http://dx.doi.org/10.3390/su6074227

Saaty, T. L. 1994. Highlights and critical points in theory and application of the Analytic Hierarchy Process, European Journal of Operational Research 74: 426-447. http://dx.doi.org/10.1016/0377-2217(94)90222-4

Šarka, V.; Zavadskas, E. K.; Ustinovicius, L.; Šarkienė, E.; Ignatavičius, $\breve{C}$. 2008. System of project multicriteria decision synthesis in construction, Technological and Economic Development of Economy 14(4): 546-565. http://dx.doi.org/10.3846/1392-8619.2008.14.546-565

Simanaviciene, R.; Liaudanskiene, R.; Ustinovichius, L. 2012. A new Synthesis Method of Structural, Technological and Safety Decisions (SyMAD-3), Journal of Civil Engineering and Management 18(2): 265-276. http://dx.doi.org/10.3846/13923730.2012.666504

Simanaviciene, R.; Liaudanskiene, R.; Ustinovichius, L. 2014. Assessing reliability of design, construction, and safety related decisions, Automation in Construction 39: 47-58. http://dx.doi.org/10.1016/j.autcon.2013.11.008

Simanaviciene, R.; Ustinovichius, L. 2012. A new approach to assessing the biases of decisions based on multiple attribute decision making methods, Electronics and Electrical Engineering 117(1): 29-32. http://dx.doi.org/10.5755/j01.eee.117.1.1048

Srdjevic, B.; Srdjevic, Z. 2013. Synthesis of individual best local priority vectors in AHP-group decision making, Applied Soft Computing 13(4): 2045-2056.

http://dx.doi.org/10.1016/j.asoc.2012.11.010
Stankevičius, V.; Karbauskaitè, J.; Burlingis, A.; Šadauskienė, J.; Morkvènas, R. 2014. Expanding the possibilities of building modernization: case study of Lithuania, Journal of Civil Engineering and Management 20(6): 819-828. http://dx.doi.org/10.3846/13923730.2014.929599

Wang, H.-C.; Jiao, W.-L.; Lahdelma, R.; Zou, P.-H. 2011. Techno-economic analysis of a coal-fired CHP based combined heating system with gas-fired boilers for peak load compensation, Energy Policy 39(12): 7950-7962. http://dx.doi.org/10.1016/j.enpol.2011.09.050

Wang, N.; Adeli, H. 2014. Sustainable building design, Journal of Civil Engineering and Management 20(1): 1-10. http://dx.doi.org/10.3846/13923730.2013.871330

Wong, K.; Fan, Q. 2012. Building information modelling (BIM) for sustainable building design, Facilities 31(3/4): 138157. http://dx.doi.org/10.1108/02632771311299412

Yoon, K.; Hwang, C. L. 1981. Topsis (technique for order preference by similarity to ideal solution) - a multiple attribute decision making), in C.-L. Wang, K. Yoon. Multiple attribute decision making - methods and applications, a state-of-the-at survey, Lecture Notes in Economics and Mathematical Systems. Berlin: Springer Verlag, 128-140.

Zavadskas, E. K.; Kaklauskas, A. 1996. Pastatu sistemotechninis ivertinimas [Multiple criteria assessment of buildings]. Vilnius: Technika. 280 p. (in Lithuanian).

Zavadskas, E. K.; Kaklauskas, A.; Banaitis, A.; Kvederyte, N. 2004. Housing credit access model: the case for Lithuania, European Journal of Operational Research 155(2): 335352. http://dx.doi.org/10.1016/S0377-2217(03)00091-2

Žèkas, V.; Martinaitis, V.; Streckienè, G.; Vilutienè, T. 2014. A quantitative evaluation of theoretical renewable energy potential of the building site, Journal of Civil Engineering and Management 20(6): 873-883. http://dx.doi.org/10.3846/13923730.2014.976589

Zolfani, S. H.; Maknoon, R.; Zavadskas, E. K. 2015. Multiple Nash Equilibriums and evaluation of strategies. New application of MCDM methods, Journal of Business Economics and Management 16(2): 290-306. http://dx.doi.org/10.3846/16111699.2014.967715

Romas RASIULIS. PhD student at Department of Construction Technology and Management, Vilnius Gediminas Technical University. Research interests: multicriteria evaluation and automated programming of technological decision in construction, construction technology and management, decision-making, energy efficiency, renovation.

Leonas USTINOVICHIUS. Professor Dr Habil at Vilnius Gediminas Technical University and Bialystok University of Technology. Education: Industrial and civil engineering, construction engineer, VISI (VGTU), 1982; Candidate of technical sciences Dnepropetrovsk ISI, 1989; Associate professor, VGTU, 1993; Doctor of technical sciences, VGTU, 1994; Doctor habilitatus, VGTU, 2003; Professor, VGTU, 2007. Research interests: multicriteria evaluation and automated programming of technological decision in construction, operational research methods, technology of construction process, quantitative and qualitative decision making methods, organization and performance of construction firm.

Tatjana VILUTIENĖ. Dr Assoc. Prof. at Department of Construction Technology and Management, Vilnius Gediminas Technical University. Doctor of Technological Sciences (civil engineering), 2004. Publications: the author and co-author of 2 textbooks for students and more than 50 scientific publications. Research interests: construction technology and management, decision-making, energy efficiency, refurbishment.

Vladimir POPOV. Dr Assoc. Prof. at Department of Reinforced Concrete and Masonry Structures Vilnius Gediminas Technical University. Doctor of Technical Sciences (civil engineering), 1994. Publications: the author and co-author of5 textbooks for students, 1 patent and more than 40 scientific publications. Research interests: computer-aided design systems and methods, Building Information Modelling and Integrated Design Technology, general theory of reinforced concrete and masonry, building structural analysis by finite element method. 